\title{
Effect of Traditional and Virtual Oral Hygiene Instruction to School Health Instructors on Plaque Index of Elementary Schoolchildren
}

\author{
Amin Golshah ${ }^{1}$, Mahya Salahshour ${ }^{2 *}$, Maryam Kiani $^{2}$, Ali Fatahi ${ }^{2}$ \\ ${ }^{1}$ Department of Orthodontics, Faculty of Dentistry, Kermanshah University of Medical Sciences, Kermanshah, Iran; ${ }^{2}$ Student \\ Research Comittee, Faculty of Dentistry, Kermanshah University of Medical Sciences, Kermanshah, Iran
}

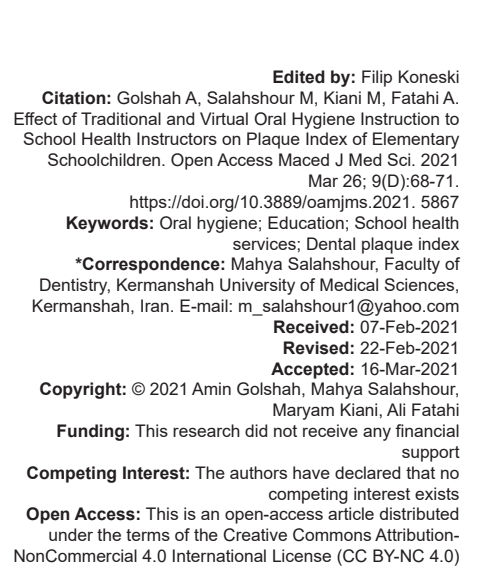

Introduction

Dental caries and periodontal disease are the most common oral and dental health conditions worldwide [1]. The time of eruption of molar teeth, especially first molars at the age of 6-7 years, corresponds to a period when children have high risk of caries. Oral hygiene measures are highly important during this particular time period, and tooth brushing at least once a day is imperative to prevent dental caries and periodontal disease [2], [3]. Oral hygiene plays a fundamental role in prevention of gingival inflammation and dental caries [3], [4]. Thus, preventive dentistry always emphasizes on oral hygiene maintenance. Oral hygiene instruction in elementary schools usually focuses on oral hygiene knowledge enhancement [3]. Correct instruction of oral hygiene measures to students plays an important role in promotion of oral health. Since children spend a lot of time at school, health care instructors play a key role in oral hygiene instruction to students. Instruction of topics related to oral and dental health and preventive measures to school health instructors can also play an important role in oral health promotion of students [5].
Lai et al., [1] in an interventional study, showed that implementation of an oral hygiene education program on 10-13 years old for one semester had a long-term positive effect on their oral health and oral hygiene status, oral habits, calculus formation, and periodontal status [1]. A descriptive, analytical study by Livny et al. [3] evaluated the efficacy of oral health promotion with an applicable approach on elementary schoolchildren emphasizing on tooth brushing skills and concluded that the mean number of tooth-brushed area increased from 2.8 to 5.7 (out of 8) after the intervention.

Virtual instruction is becoming increasingly popular worldwide. Many studies have shown its comparable or even superior efficacy compared with the traditional classroom-based education [6], [7]. Virtual instruction has advantages such as easy accessibility to the educational content anytime and anywhere, and the ability to repeat and review the taught content as desired [8]. Thus, it is growingly employed for more efficient education worldwide [9].

The plaque index $(\mathrm{PI})$ like O'Leary index [10] appears to be a commonly used oral hygiene index for assessing oral health skills and can provide sufficient information for patient education [11]. 
Considering the $\mathrm{PI}$ as an indicator of oral hygiene and the key role of school health instructors in oral hygiene instruction to elementary schoolchildren [1], this study aimed to compare the effect of traditional and virtual oral hygiene instruction to school health instructors on the PI of elementary schoolchildren. The null hypothesis was that there would be no significant difference in the efficacy of virtual instruction and traditional classroom instruction of enhance the knowledge level of school health mentors and their effect on PI of elementary schoolers.

\section{Subjects and Methods}

This descriptive, analytical study was conducted in elementary schools of Kermanshah city. The study was approved in the ethics committee of Kermanshah University of Medical Sciences (ir.kums.ac.1397.067). The study population comprised two groups. The first group comprised 66 school health instructors of elementary schools in Kermanshah city who were selected by cluster sampling. For this purpose, elementary schools of Kermanshah city were divided into three clusters based on the three educational districts of Kermanshah city. Next, the sample size for each cluster was calculated according to a previous study [5], assuming alpha $=0.05$ and study power of $90 \%$. Considering $30 \%$ dropouts, minimum sample size was calculated to be 22 individuals. The second group comprised elementary school students. Sample size for the students was calculated to be 113 students considering 10\% dropouts. A total of 339 students between 7 and 11 years were randomly selected and evaluated in this study.

This study had two phases. The first phase included assessment of the oral hygiene knowledge level of 66 school health instructors. The second phase included assessment and comparison of virtual and traditional oral hygiene instruction to instructors and their effect on PI of 339 elementary schoolchildren.

Written informed consent was obtained from the instructors before their participation in the study and they were ensured about the confidentiality of their information. A questionnaire was designed according to a previous study [5], which included 25 questions. The validity of the questionnaire was evaluated by five faculty members of Kermanshah University of Medical Sciences, School of Dentistry, who were experts in this field. Their comments were applied to the questionnaire. The validity of the questionnaire was evaluated by testing it on $10 \%$ of the study population. The validity of the first 14 questions of the questionnaire was calculated to be 0.90 according to the Kuder Richardson formula and that of the remaining 11 questions was calculated to be $79 \%$ using the Cronbach's alpha, which indicated moderate validity of the questionnaire [5]. The questionnaire also asked for demographic information of school health instructors including their age, gender, work experience, and level of education. The main part of the questionnaire included basic questions regarding the level of knowledge of instructors about oral hygiene.

Next, they were randomly divided into two groups ( $n=33$ ) and correct oral hygiene including correct tooth brushing, dental flossing, and healthy nutritional habits were instructed to school health instructors. The first group received these instructions online by watching a short film and some pictures of the process, while the second group received a traditional classroom education on dental models and written instructions. The both groups were requested to provide oral hygiene instructions that they were taught to students within three sessions (once a week).

After obtaining written informed consent from the parents or legal guardians of children, the PI of elementary schoolers was measured at baseline before the intervention using the O'Leary's index [10]. The school health instructors had $1 \mathrm{~h}$ of self-study by watching of the short film and process pictures or traditional education by reading the written instructions, depending on their group allocation. After 3 weeks, the same questionnaires were administered again among the same school health instructors and their responses were recorded and compared with their responses at baseline. After 3 months, the students were then divided into two groups of virtual instruction and traditional instruction, based on their school instructor education. Then, the PI of students was measured again to assess the effect of oral hygiene instruction.

Data were analyzed using SPSS version 25 (SPSS Inc., IL, USA). The Chi-square test was used to assess the correlation of level of education (qualitative variable) with knowledge score of instructors. The measures of central dispersion were reported for quantitative variables, namely, age and work experience. Normal distribution of data was evaluated using the Kolmogorov-Smirnov test, and the Levene's test was applied to assess the homogeneity of variances. ANOVA was used to assess the correlation of quantitative variables with the knowledge level. t-test and Chi-square test were applied to compare the effects of virtual and traditional instruction on $\mathrm{PI}$ of students.

\section{Results}

Of 339 students, 7 did not show up for the second assessment. Thus, data of 332 students were statistically analyzed. Of 66 school health instructors, $40(60.60 \%)$ were female and $26(39.4 \%)$ were male. The mean age of school health instructors was 42.82 \pm 6.34 years (range 30-53 years). Regarding the level of education of school health instructors, $1.5 \%(n=1)$ 
had high school diploma, $18.2 \%(n=12)$ had college degree, $72.7 \%$ ( $n=48$ ) had bachelor's degree, and $7.6 \%(n=5)$ had master's degree. The school health instructors had a mean work experience of $18.53 \pm 8.48$ years (range 3-38 years).

Of elementary students, $51.20 \%(n=170)$ were female and $48.79 \%(n=162)$ were male.

Table 1 presents the mean $\mathrm{Pl}$ before and after oral hygiene instruction by instructors in the virtual and traditional instruction groups. As shown, virtual instruction had a positive effect on PI of children $(p<0.001)$. Traditional instruction also showed a positive effect on PI of students $(p<0.001)$. Comparison of virtual and traditional instructions by the Mann-Whitney U-test revealed that virtual instruction had a significantly greater positive effect on PI of students $(p<0.001)$.

Table 1: Mean PI before and after oral hygiene instruction by instructors in the virtual and traditional instruction groups $(n=166)$

\begin{tabular}{llllll}
\hline Group & Variable & Mean & Std. deviation & $\mathrm{t}$ & $\mathrm{p}$-value \\
\hline $\begin{array}{l}\text { Virtual instruction } \\
\text { (paired t-test) }\end{array}$ & $\begin{array}{l}\text { PI before the } \\
\text { intervention } \\
\text { Pl after the }\end{array}$ & 36.28 & 17.03 & 8.096 & $<0.001$ \\
intervention & & 9.58 & & \\
Traditional instruction & $\begin{array}{l}\text { Pl before the } \\
\text { intervention }\end{array}$ & 44.46 & 18.39 & -9.45 & $<0.001$ \\
(Wilcoxon test) & $\begin{array}{l}\text { Pl after the } \\
\text { intervention }\end{array}$ & 30.16 & 15.80 & & \\
\hline
\end{tabular}

Table 2 presents the knowledge score of school health instructors before and after virtual and traditional oral hygiene instructions. As shown, both virtual and tradition instructions significantly enhanced the knowledge of school health instructors about oral hygiene ( $p<0.001)$. However, according to the MannWhitney U-test, virtual instruction was more effective than traditional instruction $(p=0.02)$.

Table 2: Knowledge score of school health instructors before and after virtual and traditional oral hygiene instruction $(n=33)$

\begin{tabular}{llllll}
\hline Group & Variable & Mean & Std. deviation & $\mathrm{t}$ & $\mathrm{p}$-value \\
\hline $\begin{array}{l}\text { Virtual } \\
\text { instruction }\end{array}$ & $\begin{array}{l}\text { Knowledge score } \\
\text { before the intervention } \\
\text { (Wilcoxon test) }\end{array}$ & 17.18 & 2.66 & -3.66 & $<0.001$ \\
$\begin{array}{l}\text { Knowledge score after } \\
\text { the intervention }\end{array}$ & 19.29 & 3.20 & & \\
$\begin{array}{l}\text { Traditional } \\
\text { instruction } \\
\text { (paired t-test) }\end{array}$ & $\begin{array}{l}\text { Knowledge score } \\
\text { before the intervention } \\
\text { Knowledge score after } \\
\text { the intervention }\end{array}$ & 14.79 & 3.31 & -5.92 & $<0.001$ \\
\hline
\end{tabular}

The Spearman's correlation test revealed no significant correlation between work experience of instructors and the knowledge score in virtual instruction group $(p=0.16)$. However, work experience of instructors had an inverse correlation with the knowledge score in traditional instruction group $(p=0.01)$.

The Spearman's correlation test revealed no significant correlation between the age of instructors with their level of knowledge in the virtual instruction group ( $p=0.35$ ). However, age of instructors had an inverse correlation with knowledge level in traditional instruction group $(p=0.002)$.

Level of education of instructors had no significant correlation with their knowledge level in virtual or traditional instruction group (one-way ANOVA, $p>0.05)$.

\section{Discussion}

This study compared the effect of traditional and virtual oral hygiene instruction to school health instructors on $\mathrm{Pl}$ of elementary schoolchildren. The results showed that both instruction methods significantly enhanced the oral hygiene knowledge of instructors $(p<0.001)$ but virtual instruction was significantly more effective $(p=0.02)$.

As shown, oral hygiene status of elementary schoolchildren was not favorable, which calls for implementation of some educational programs in this respect. Oral hygiene promotion in elementary schools should be based on knowledge enhancement and instruction of oral hygiene measures [3]. School health instructors can play a key role in this process. Our study showed poor knowledge level of school health instructors regarding oral hygiene. Most school health instructors had not participated in any course regarding oral hygiene and had not received any education in this respect. Thus, it is imperative to hold some educational courses for school health instructors to enhance their level of knowledge in this respect.

Our results showed significant effect of both virtual and traditional instructions on knowledge score of instructors; however, this effect was greater in the virtual instruction group. This finding was in agreement with that of Bassir et al. [5] Hartshorne et al. [12] reported that implementation of oral hygiene programs in schools can effectively improve oral hygiene. Bassir et al. [13] evaluated the effect of oral health education on PI of children in Ahwaz and reported that oral health education decreased the DI-S index of students. Our results were in line with their findings. Halonen et al. [2] and Lai et al. [1] evaluated oral health behaviors of children and reported the positive effect of education on knowledge level of oral health instructors and its consequent effect on promotion of oral health of students, which was in agreement with our findings. Jabari et al. [14] compared three methods of oral hygiene instruction to students in Ahwaz and reported that although oral hygiene of students was better in the virtual education group, OHI-S index was higher in the traditional instruction group, which was in contrast to our findings since our study showed that virtual instruction had a significantly greater positive effect on $\mathrm{PI}$ of children. This difference between the results of the two studies can be due to different methodologies. Basir et al. [15] showed significant effect of oral hygiene instruction on oral hygiene improvement of students. However, they provided traditional oral hygiene instruction using a dental model, which was different from our methodology. 
Our study showed no significant correlation between level of education of school health instructors and their knowledge level in virtual or traditional instruction groups, which was in line with the results of Bassir et al. [5], [13] However, in our study, work experience and age of instructors had no significant correlation with their knowledge level in the virtual instruction group, which was in line with the results of Bassir et al. [5].

This study had some limitations. The effects of instructions were evaluated after 3 months, which is not long enough for the assessment of long-term effects of instructions. Thus, further long-term studies are required to assess the effect of such instructions in long term. Furthermore, the process of instruction should be continuous [16]. There is a possibility that instructors did not provide oral hygiene instructions to students in a regular weekly basis. Furthermore, the number of male and female students was not equal in our study, which was another limitation, and thus, we could not compare male and female students.

Considering the significant role of school health mentors in oral hygiene of students, oral hygiene instructions should be included in the educational curriculum of health instructors. Role of parents is also highly important in oral hygiene of students, which should be addressed in future studies. Last but not least, considering the increasing interest of young generation in virtual social media, the social media can be used to promote oral hygiene of students and can be an interesting topic for future research.

\section{Conclusion}

Correct oral hygiene instruction to school health instructors can enhance their knowledge level and reduce PI schoolchildren. However, virtual instruction was significantly more effective than traditional instruction.

\section{References}

1. Lai H, Fann JC, Yen AM, Chen LS, Lai MH, Chiu SY. Longterm effectiveness of school-based children oral hygiene program on oral health after 10-year follow-up. Community Dent Oral Epidemiol. 2016;44(3):209-15. https://doi.org/10.1111/ cdoe. 12207

PMid:26691608

2. Halonen H, Pesonen P, Seppa L, Peltonen E, Tjaderhane L, Anttonen V. Outcome of a community-based oral health promotion project on primary schoolchildren's oral hygiene habits. Int J Dent. 2013;2013:485741. https://doi.org/10.1155/2013/485741 PMid:24319461

3. Livny A, Vered $\mathrm{Y}$, Slouk L, Sgan-Cohen HD. Oral health promotion for schoolchildren evaluation of a pragmatic approach with emphasis on improving brushing skills. BMC Oral Health. 2008;8:4. https://doi.org/10.1186/1472-6831-8-4

PMid: 18237389

4. Lang NP, Cumming BR, Loe $\mathrm{H}$. Toothbrushing frequency as it relates to plaque development and gingival health. J Periodontol. 1973;44(7):396-405. https://doi.org/10.1902/jop.1973.44.7.396 PMid:4514570

5. Bassir L, Khanehmasjedi M, Falahi HR. Evaluation of the effectiveness of education on awareness of hygiene teachers in primary schools of ahvaz on preventive orthodontics in educational year 2005-2006. Jundishapur Sci Med J. 2013;12:99-104.

6. Jenkins S, Goel R, Morrell DS. Computer-assisted instruction versus traditional lecture for medical student teaching of dermatology morphology: A randomized control trial. J Am Acad Dermatol 2008;59(2):255-9. https://doi.org/10.1016/j. jaad.2008.04.026

PMid:18499299

7. Tarpada SP, Hsueh WD, Gibber MJ. Resident and student education in otolaryngology: A 10-year update on e-learning. Laryngoscope. 2017;127(7):E219-24. https://doi.org/10.1002/ lary. 26320

PMid:27782300

8. Varnum KJ. Beyond Reality: Augmented, Virtual, and Mixed Reality in the Library. Chicago, Illinois: American Library Association; 2019. https://doi.org/10.1177/0961000619890757

9. Nagendrababu V, Pulikkotil SJ, Sultan OS, Jayaraman J, Soh JA, Dummer PM. Effectiveness of technology-enhanced learning in endodontic education: A systematic review and meta-analysis. Int Endod J. 2019;52(2):181-92. https://doi. org/10.1111/iej.12995

PMid:30099740

10. O'Leary TJ, Drake RB, Naylor JE. The plaque control record. J Periodontol. 1972;43(1):38.

PMid:4500182

11. Silberman SL, Le Jeune RC, Serio FG, Devidas $M$, Davidson L, Vernon K. A method for determining patient oral care skills: The University of Mississippi oral hygiene index. J Periodontol. 1998;69(10):1176-80. https://doi.org/10.1902/ jop.1998.69.10.1176

PMid:9802720

12. Hartshorne JE, Carstens IL, Beilinsohn B, Potgieter G. The effectiveness of a school-based oral health education program--a pilot study. J Dent Assoc S Afr. 1989;44(1):5-10. PMid:2609352

13. Bassir L, Khanehmasjedi M, Dashtbozorgi B. Evaluation of the effect of repetition of oral health education in 9-10 years old students' plaque index. Sci Med J. 2009;8(2):219-29.

14. Jabari L, Gharizadeh N, Bassir L. Comparative evaluation of three method of oral hygiene instruction (OHIS) in grade 3 and 4 students in ahvaz. Jundishapur Sci Med J 2005;12(1):99-104.

15. Basir L, Araban M, Khanehmasjedi M, Khanehmasjedi S. The effect of oral health literacy of adolescents on their oral health status: A cross-sectional study from Southwestern Iran. J Oral Health Oral Epidemiol. 2020;9(4):173-9. https://doi.org/10.1186/ s12903-021-01447-w

16. Tolvanen $M$, Lahti $S$, Hausen $H$. Changes in toothbrushing frequency in relation to changes in oral health-related knowledge and attitudes among children-a longitudinal study. Eur J Oral Sci. 2010;118(3):284-9. https://doi. org/10.1111/j.1600-0722.2010.00737.x

PMid:20572863 